\title{
Effect of the Dressing Process on the Surface Roughness in Cylindrical Grinding of Ti6A14V Alloy Using Stationary Diamond Dressing Tools
}

\author{
Mikhail Khramenkov (0000-0002-1977-7595), Jan Jersák (0000-0001-7773-4780) \\ Department of Machining and Assembly, Faculty of Mechanical Engineering, Technical University of Liberec. \\ 461 17, Studentská 1402/2, Liberec 1, Czech Republic. \\ E-mail: khrmih@gmail.com, jan.jersak@tul.cz
}

The current study investigates the influence of the dressing process of the vitrified bonded microcrystal alumina grinding wheel on the roughness of the machined surfaces in cylindrical grinding of Ti6Al4V alloy using different types of stationary diamond dressing tools. For the research, four types of dressers were selected, which differ from each other by number, size and location of diamond cutting elements. Each dresser has been tested at four different dressing feed values with the same dressing depth. Two sets of experiments were conducted to determine the tendency of grinded parts roughness parameters change depending on the dressing feed for each type of diamond dressing tool at two values of grinding feed. A comparative analysis was carried out to show the dressing feed influence and the effect of the diamond dresser type select on the roughness parameters of the grinded surfaces.

Keywords: Cylindrical Grinding, Stationary Diamond Dressing Tools, Roughness, Ti6Al4V Alloy

\section{Introduction}

Titanium alloy Ti6Al4V is widely used in many industries, including medicine, aerospace and racing industries [1-4]. The dressing process significantly affects the geometry of the grinding wheel surface, and as a result, influences on the surface quality of grinded parts [5-12]. Often, when grinding titanium alloys, the grinding wheel wears out quickly in comparison with grinding of other materials, therefore, when grinding Ti6Al4V, grinding wheels have to be dressed frequently. Many types of stationary diamond dressing tools are applied in industry and it is not evident from existing studies [13-16] which type of dressing tool and with which dressing feed values is better to select from the points of view of dressing process productivity and grinded parts roughness parameters for efficiency of the circular grinding of Ti6Al4V alloy. The choise of the right type of stationary dressing tool and suitable dressing feed value can improve quality of the grinded surfaces, reduce dressing time and generally reduce the cost of the Ti6Al4V grinding process. Thus, the article determines the effect of four commonly used types of stationary diamond dressing tools on the machined surfaces roughness parameters of the Ti6Al4V alloy at different values of dressing feed at two different grinding feed rates of the circular grinding process.

\section{Experimental procedures}

For determination grinded surface roughness parameters when using different stationary diamond dressing tools with different dressing feed values at two grinding feed rates, the experiments were conducted by dressing and grinding on the grinding machine for circular grinding BERNARDO URS 500 N (Fig. 1).



Fig. 1 Grinding wheel dressing process using single-point dresser on the grinding machine BERNARDO URS $500 \mathrm{~N}$

Four commonly used stationary diamond dressing tools were selected, which differ from each other by number, size and location of diamond cutting elements (Tab. 1). For each dresser the approximate contact length with the grinding wheel in the direction of dressing feed was measured using confocal microscope KEYENCE VK-X1100. 
Tab. 1 Used stationary diamond dressing tools

Dresser type

Approximate width of contact

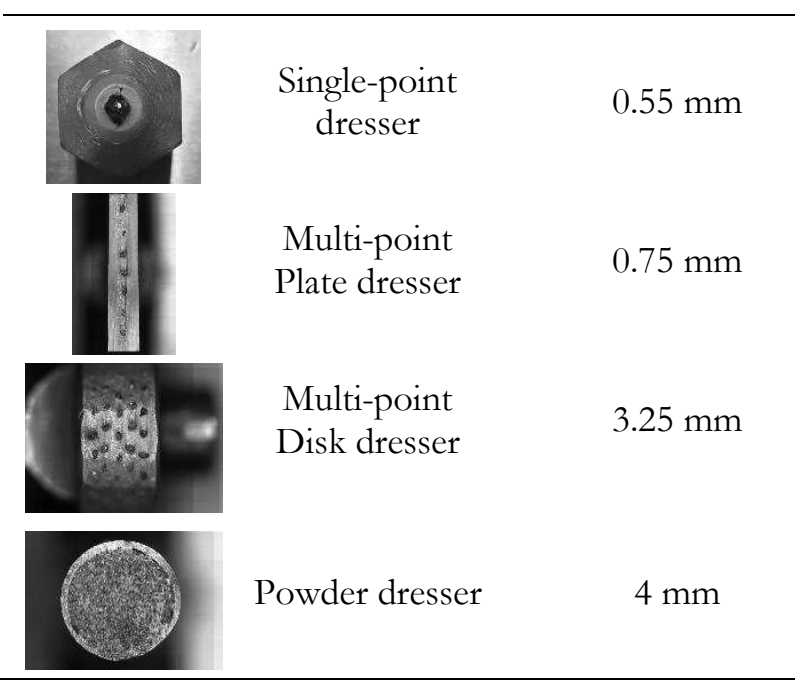

Grinding of Ti6Al4V alloy (361 HV) was performed with the TYROLIT vitrified bonded microcrystal alumina grinding wheel T1 400x50x203 454A 801 J10 $\mathrm{V} 3$ at the average cutting speed of $v_{c}=35,45 \mathrm{~m} / \mathrm{s}$, with two values of the grinding machine table feed: $v_{f}=0.25$ $\mathrm{m} / \mathrm{min}$ and $v_{f}=1.0 \mathrm{~m} / \mathrm{min}$. For each experiment 5 double passes with the depth of cut $a_{p}=10 \mu \mathrm{m}$ were conducted and then 10 passes were made without further depth of cut increasing. The workpiece rotation speed was kept constant at the value of 15 $\mathrm{m} / \mathrm{min}$. The grinded length of the Ti6Al4V workpieces was $20 \mathrm{~mm}$.

Processes of grinding and dressing were conducted using cutting fluid BLASER BlASOCUT BC 25 MD based on mineral oil. For all dressing and grinding operations, 3\% mixture of cutting fluid concentrate and water was applied. The cutting fluid concentration was measured by the Optech Brix RLC / ATC refractometer, which is capable of measuring concentration at the range of $0-18 \%$ and with $0.1 \%$ accuracy.

Experiments were carried out applying four values of the dressing feed, namely at dressing feed rates of $f_{\mathrm{d}}=0.035,0.105,0.315,0.945 \mathrm{~mm} /$ rev. For every experiment 5 dressing passes with the dressing depth $a_{d}$ $=0.020 \mathrm{~mm}$ were conducted to avoid leaving the processed material in pores of the grinding wheel.

Measurements of the roughness parameters were conducted using the profilometer MITUTOYO Surflest SV-2000 N2. For every experiment roughness measurement was repeated 10 times around the circumference of the workpieces in the direction of the workpiece axis, and based on this, the average roughness parameters values were determined.

As mentioned above, for each of the four dressers, four different dressing feed rates were used, resulting in 16 different grinding wheel surface topographies. The actual cylindrical grinding process was additionally implemented with two different grinding feed rates for each case. In total, there were 32 different grinding variants. To ensure the reliability of the research results, each grinding variant was repeated 5 times.

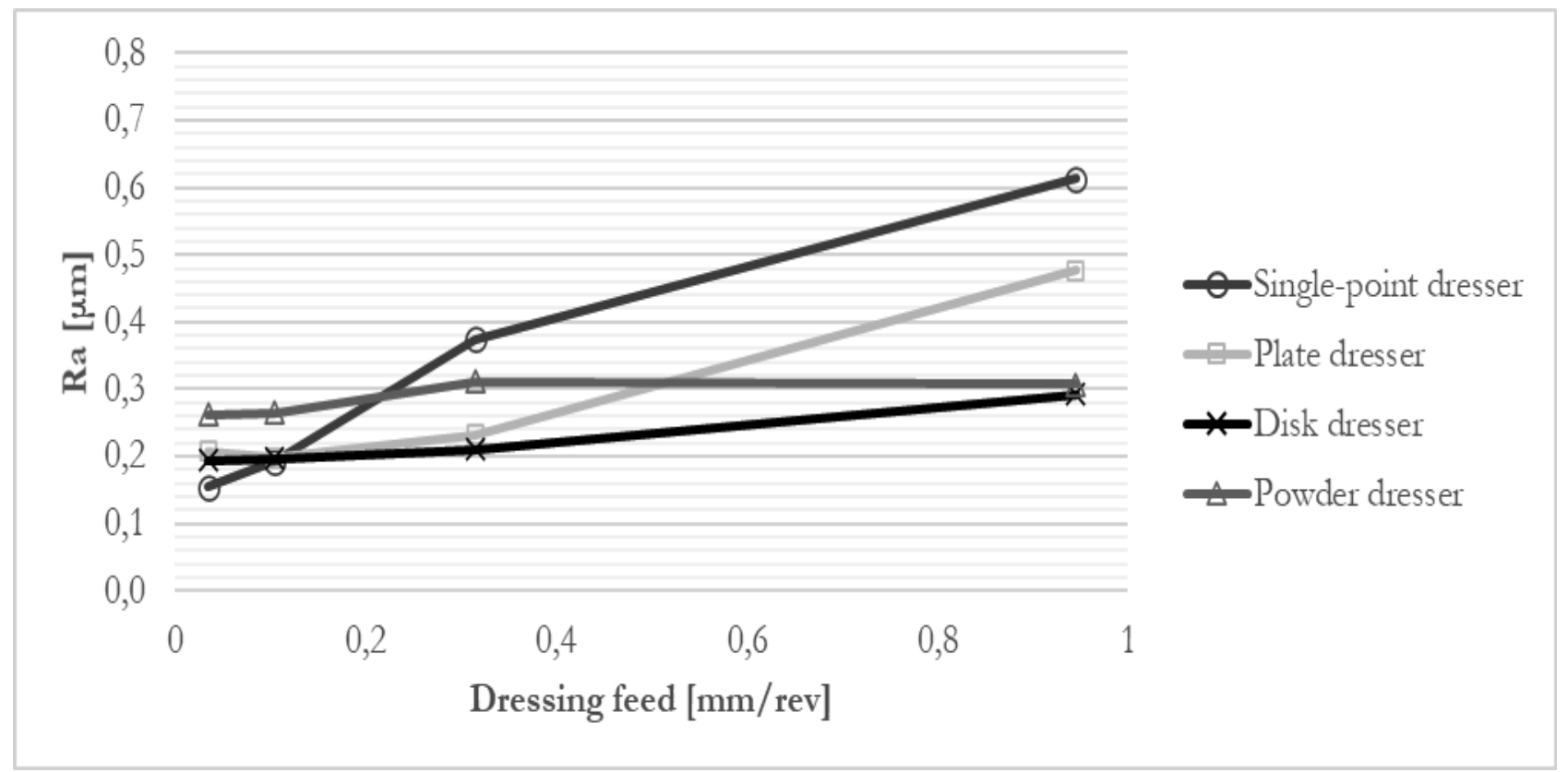

Fig. 2 The effect of dressing feed for different dressers on the parameter $\mathrm{R} a$ at $0.25(\mathrm{~m} / \mathrm{min})$ grinding feed 


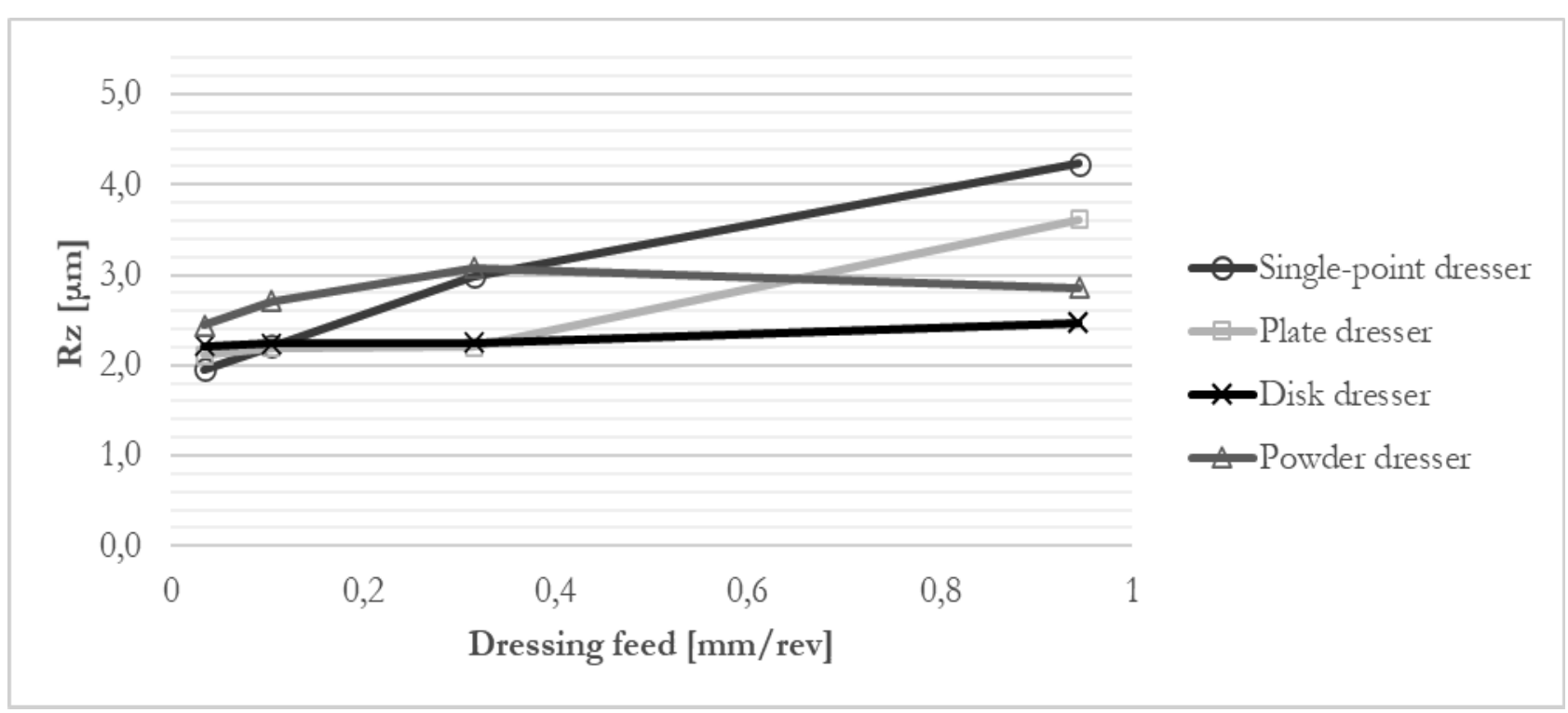

Fig. 3 The effect of dressing feed for different dressers on the parameter $\mathrm{R}_{z}$ at $0.25(\mathrm{~m} / \mathrm{min})$ grinding feed

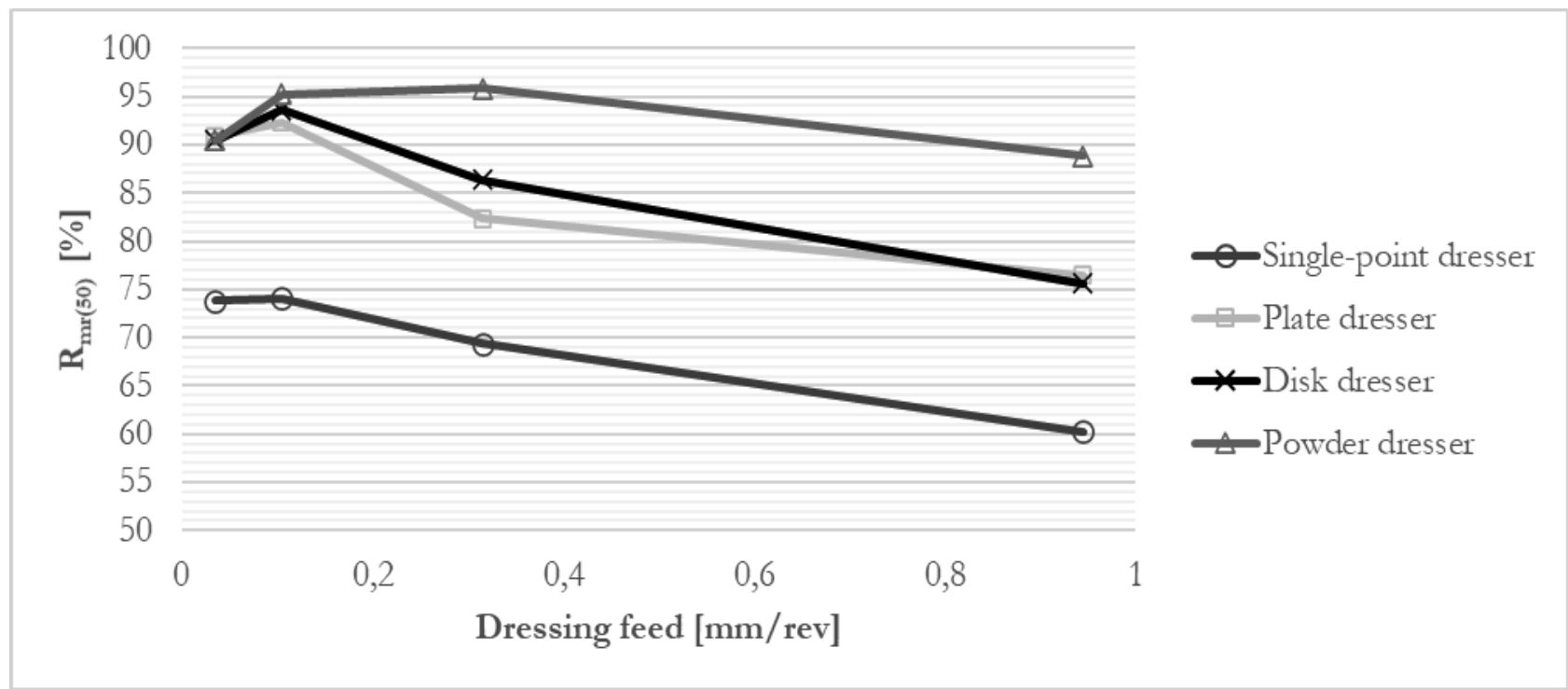

Fig. 4 The effect of dressing feed for different dressers on the parameter $\mathrm{Rmr}(50)$ at $0.25(\mathrm{~m} / \mathrm{min})$ grinding feed

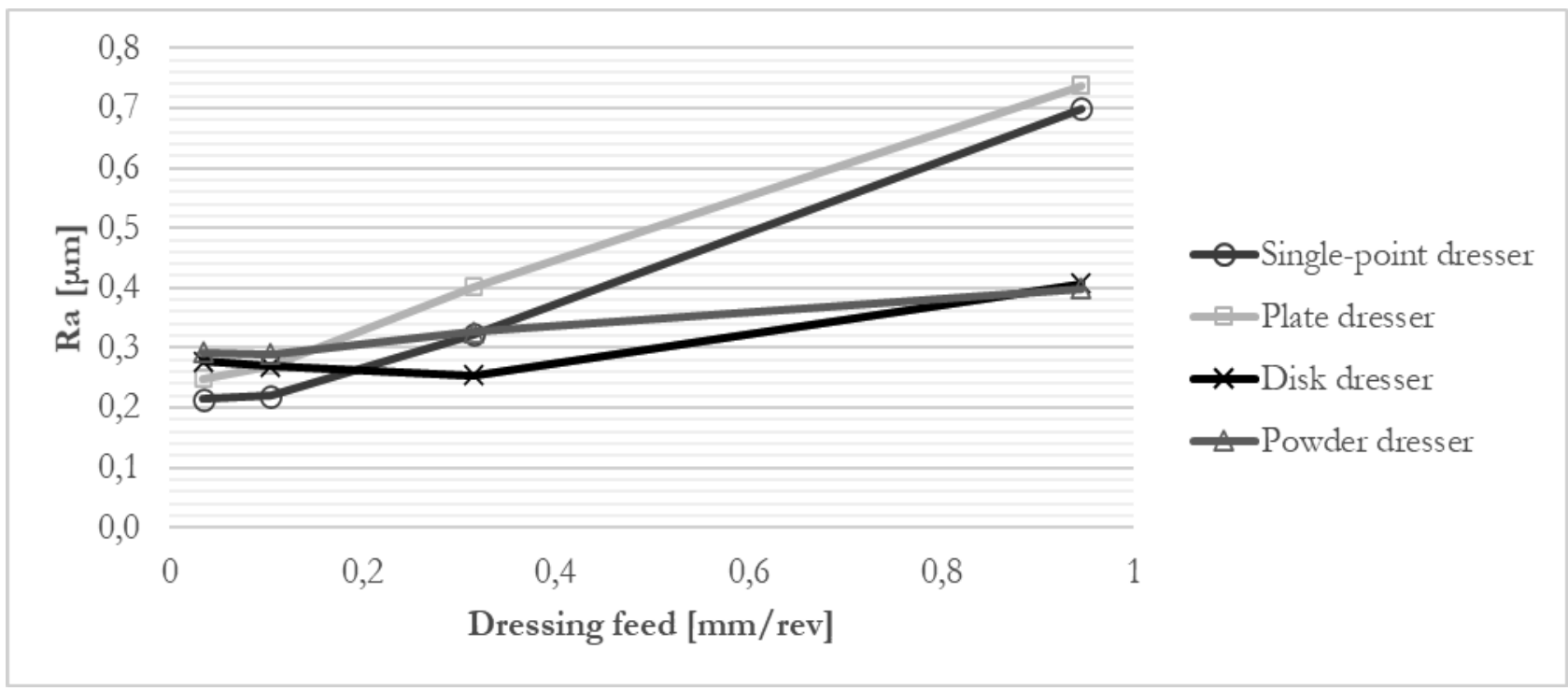

Fig. 5 The effect of dressing feed for different dressers on the parameter $\mathrm{R} a$ at $1.0(\mathrm{~m} / \mathrm{min})$ grinding feed 


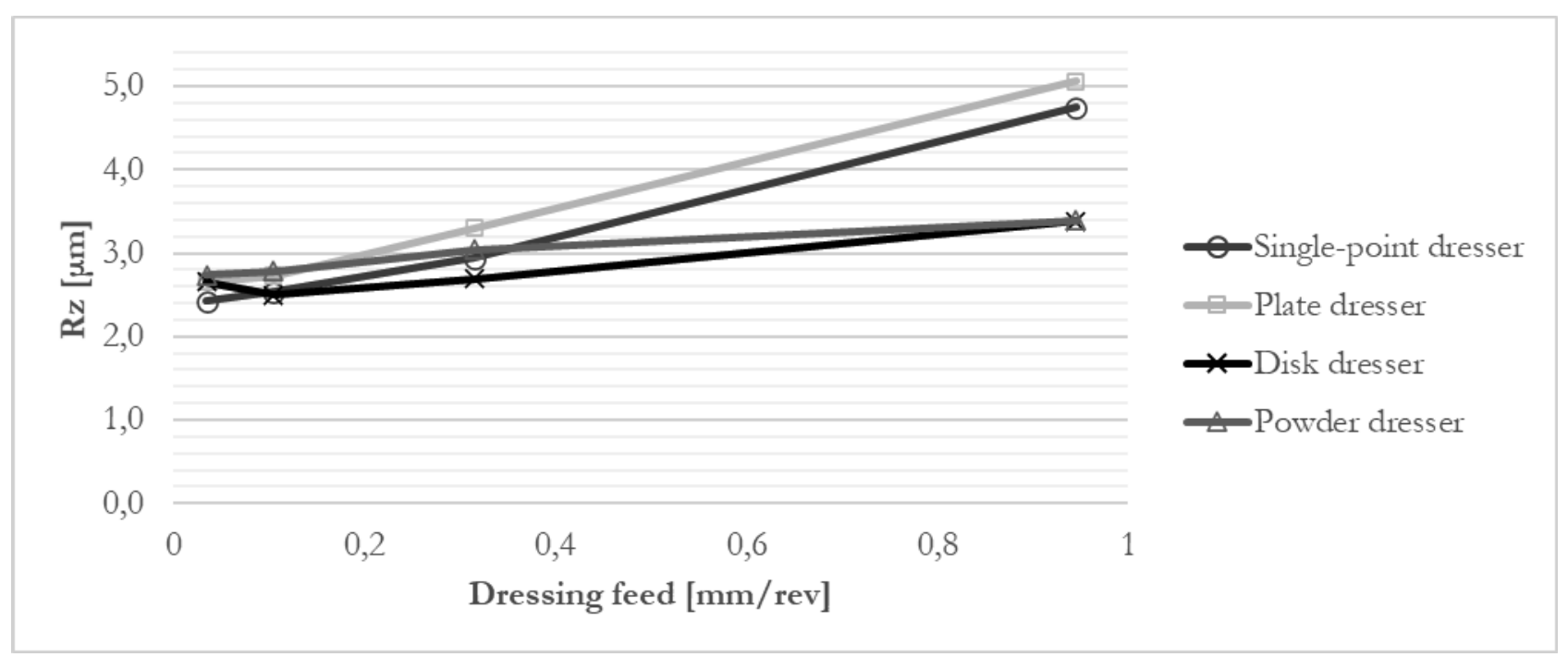

Fig. 6 The effect of dressing feed for different dressers on the parameter $\mathrm{Rz}$ at $1.0(\mathrm{~m} / \mathrm{min})$ grinding feed

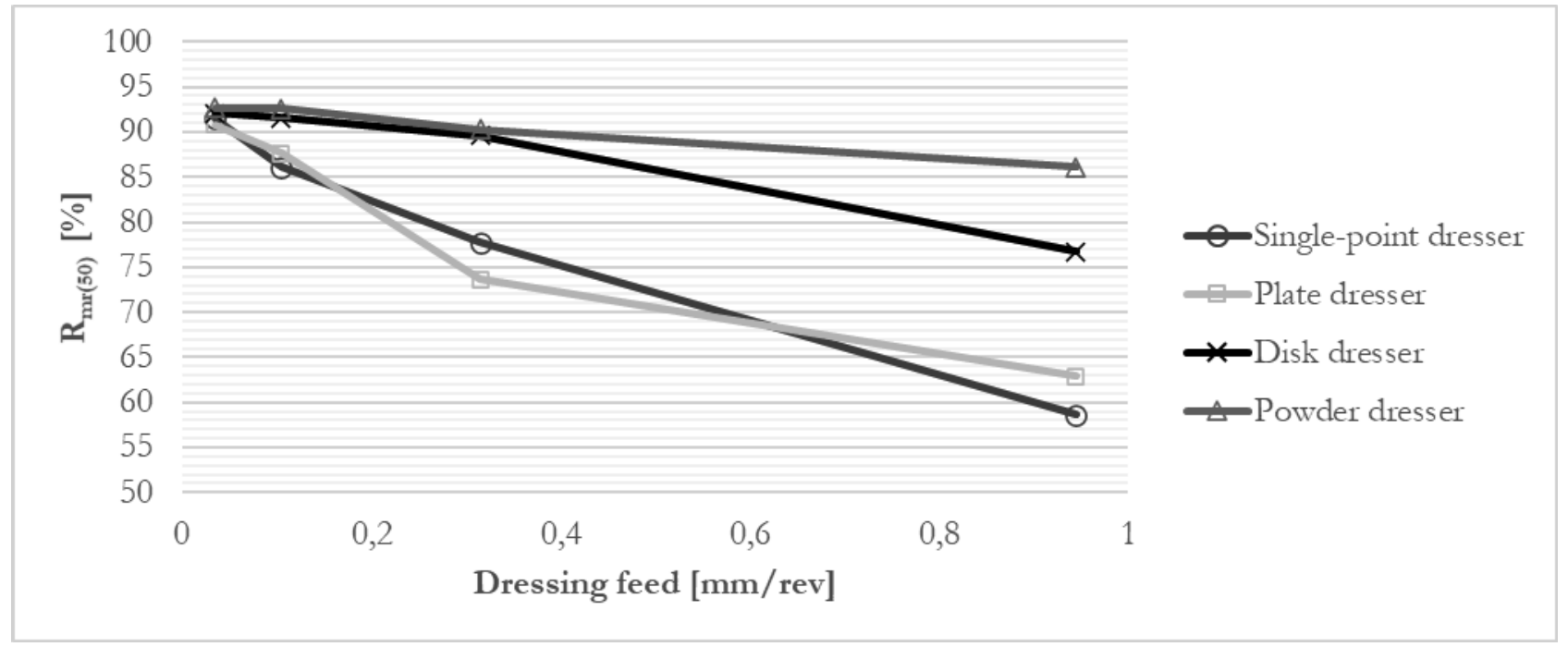

Fig. 7 The effect of dressing feed for different dressers on the parameter Rmr(50) at $1.0(\mathrm{~m} / \mathrm{min})$ grinding feed

\section{Discussion of results}

After processing the experimental data, it was found that at $0.035 \mathrm{~mm} / \mathrm{rev}$ dressing feed with 0.25 $\mathrm{m} / \mathrm{min}$ grinding feed the lowest roughness parameter $\mathrm{R} a$ is produced applying single-point diamond dresser. The application of the multi-point disk dresser enlarges the $R a$ parameter by $26 \%$, the application of the multi-point plate dresser enlarges the Ra parameter by $34 \%$, and the application of the powder diamond dresser enlarges the $\mathrm{R} a$ parameter by $70 \%$. For 0.945 $\mathrm{mm} /$ rev dressing feed with $0.25 \mathrm{~m} / \mathrm{min}$ grinding feed the application of the disk dresser produces the lowest value of the roughness parameter $R a$. The application of the powder dresser enlarges the $\mathrm{R} a$ parameter by $5 \%$, while the application of the multi-point plate dresser enlarges the $\mathrm{R} a$ parameter by $63 \%$. Application of the single-point diamond dresser shows the worst results, namely the increase of the roughness parameter $R a$ by 2.1 times. Also, the increase of the dressing feed from $0.035 \mathrm{~mm} / \mathrm{rev}$ to $0.945 \mathrm{~mm} / \mathrm{rev}$ with 0.25 $\mathrm{m} /$ min grinding feed can cause $17 \%$ of the roughness parameter Ra increase for the powder dresser, $51 \%$ increase for the multi-point disk dresser, 2.3 times increase for the multi-point plate dresser, and 3.97 times increase for the single-point dresser (Fig. 2). These results can be explained by the fact, that powder and disk dressers have a wider contact with the grinding wheel in the direction of the dressing feed in comparison with single-point and plate diamond dressing tools (Tab.1). And as a consequence, powder and disk dressers have higher values of the overlap coefficient, which can be calculated as the ratio of the contact width between dresser and grinding wheel in the direction of the dressing feed to the dressing feed value.

The studies have shown that at $0.035 \mathrm{~mm} / \mathrm{rev}$ dressing feed with $1.0 \mathrm{~m} / \mathrm{min}$ grinding feed the lowest parameter $R a$ is produced applying single-point diamond dresser. The application of the multi-point plate dresser enlarges the $\mathrm{R} a$ parameter by $16 \%$, the application of the multi-point disk dresser enlarges the $\mathrm{R} a$ 
parameter by $30 \%$, and the application of the powder diamond dresser enlarges the $\mathrm{R} a$ parameter by $36 \%$. For $0.945 \mathrm{~mm} / \mathrm{rev}$ dressing feed with $1.0 \mathrm{~m} / \mathrm{min}$ grinding feed the application of powder and disk dressers produces approximately the same low values of the parameter $R a$. The application of the singlepoint diamond dresser enlarges the $\mathrm{R} a$ parameter by the $75 \%$, whereas the application of the multi-point plate dresser increases the roughness parameter R $a$ by $84 \%$. Also, the increase of the dressing feed from $0.035 \mathrm{~mm} / \mathrm{rev}$ to $0.945 \mathrm{~mm} / \mathrm{rev}$ with $1.0 \mathrm{~m} / \mathrm{min}$ grinding feed can cause $37 \%$ of the roughness parameter $\mathrm{R} a$ increase for the powder dresser, $47 \%$ increase for the multi-point disk dresser, 2.95 times increase for the multi-point plate dresser, and 3.26 times increase for the single-point dresser (Fig. 5).

It has been established that at $0.035 \mathrm{~mm} / \mathrm{rev}$ dressing feed with $0.25 \mathrm{~m} / \mathrm{min}$ grinding feed the lowest $\mathrm{R}$ z parameter is produced applying single-point diamond dresser. The application of the multi-point plate dresser enlarges the $R \approx$ parameter by $8 \%$, the application of the multi-point disk dresser enlarges the $R \approx p a-$ rameter by $13 \%$, and the application of the powder diamond dresser enlarges the $R_{z}$. parameter by $25 \%$. For $0.945 \mathrm{~mm} / \mathrm{rev}$ dressing feed with $0.25 \mathrm{~m} / \mathrm{min}$ grinding feed the application of the disk dresser produces the lowest value of the roughness parameter $R \approx$ : The application of the powder dresser enlarges the $R_{z}$ parameter by $16 \%$, whereas the application of the multipoint plate dresser enlarges the roughness parameter $R \approx$ by $46 \%$. Applying of the single-point diamond dresser shows the worst results, namely the increase of the $R_{z}$. roughness parameter by $71 \%$. Also, the increase of the dressing feed from $0.035 \mathrm{~mm} / \mathrm{rev}$ to $0.945 \mathrm{~mm} / \mathrm{rev}$ with $0.25 \mathrm{~m} / \mathrm{min}$ grinding feed can cause $12 \%$ of the roughness parameter $R z$ increase for the multi-point disk dresser, $17 \%$ increase for the powder dresser, $71 \%$ increase for the multi-point plate dresser, and 2.16 times increase for the single-point dresser (Fig. 3).

The comparative analysis has shown that at 0.035 $\mathrm{mm} / \mathrm{rev}$ dressing feed with $1.0 \mathrm{~m} / \mathrm{min}$ grinding feed the lowest parameter $R z$ is produced applying singlepoint diamond dresser. The application of multi-point plate and disk dressing tools enlarges the $\mathrm{R} \approx$ parameter by $9 \%$, and the application of the powder dresser enlarges the $R_{z}$. parameter by $13 \%$. For $0.945 \mathrm{~mm} / \mathrm{rev}$ dressing feed with $1.0 \mathrm{~m} / \mathrm{min}$ grinding feed the application of powder and disk dressers produces approximately the same low values of the $R \approx$ parameter. The application of the single-point diamond dresser enlarges the $R \approx$ parameter by $40 \%$, while the application of the multi-point plate dresser enlarges the $R \approx$ roughness parameter by $49 \%$. Also, the increase of the dressing feed from $0.035 \mathrm{~mm} / \mathrm{rev}$ to $0.945 \mathrm{~mm} / \mathrm{rev}$ with $1.0 \mathrm{~m} / \mathrm{min}$ grinding feed can cause $24 \%$ of the roughness parameter $R_{\gtrless}$. increase for the powder dresser, 28\% increase for the multi-point disk dresser, $90 \%$ increase for the multi-point plate dresser, and $96 \%$ increase for the single-point diamond dresser (Fig. 6).

The value of the $R_{\operatorname{mr}(50)}$ parameter characterizes the percentage of the material component of the roughness profile at the $50 \%$ profile level depth. It is considered, that for reliability, a high value of this parameter is better, because surfaces with a low $R_{m r(50)}$ parameter value are more susceptible to wear. The experiments have shown that at $0.035 \mathrm{~mm} / \mathrm{rev}$ dressing feed with $0.25 \mathrm{~m} / \mathrm{min}$ grinding feed the same high roughness parameter $R_{m r(50)}$ is provided applying multipoint plate, disk and powder diamond dressing tools. The application of the single-point diamond dresser decreases the roughness parameter $R_{\operatorname{mr}(50)}$ by $18 \%$. For $0.945 \mathrm{~mm} / \mathrm{rev}$ dressing feed with $0.25 \mathrm{~m} / \mathrm{min}$ grinding feed the use of the powder dresser produces the highest value of the roughness parameter $R_{m r(50)}$. The application of plate and disk dressing tools decreases the parameter $R_{m r(50)}$ by $14 \%$, whereas the application of the single-point diamond dresser decreases the roughness parameter $R_{m r}(50)$ by $32 \%$. Also, the increase of the dressing feed from $0.035 \mathrm{~mm} / \mathrm{rev}$ to 0.945 $\mathrm{mm} / \mathrm{rev}$ with $0.25 \mathrm{~m} / \mathrm{min}$ grinding feed can cause $2 \%$ of the roughness parameter $R_{m r(50)}$ decrease for the powder dresser, $16 \%$ decrease for multi-point plate and disk dressers, and 18\% decrease for the singlepoint diamond dresser (Fig. 4).

The studies have shown that at $0.035 \mathrm{~mm} / \mathrm{rev}$ dressing feed with $1.0 \mathrm{~m} / \mathrm{min}$ grinding feed all tested types of stationary diamond dressing tools provide the same high roughness parameter $R_{\operatorname{mr}(50)}$ values. For $0.945 \mathrm{~mm} / \mathrm{rev}$ dressing feed with $1.0 \mathrm{~m} /$ min grinding feed the use of the powder dresser produces the highest value of the roughness parameter $R_{m r(50)}$. The application of the disk dresser decreases the parameter $R_{\operatorname{mr}(50)}$ by $11 \%$, while the use of the multi-point plate dresser decreases the roughness parameter $R_{\operatorname{mr}(50)}$ by $27 \%$, and the use of the single-point diamond dresser decreases the roughness parameter $R_{m r(50)}$ by $32 \%$. Also, the increase of the dressing feed from 0.035 $\mathrm{mm} / \mathrm{rev}$ to $0.945 \mathrm{~mm} / \mathrm{rev}$ with $1.0 \mathrm{~m} / \mathrm{min}$ grinding feed can cause $7 \%$ of the roughness parameter $R_{\operatorname{mr}(50)}$ decrease for the powder dresser, $17 \%$ decrease for the multi-point disk dresser, $31 \%$ decrease for the multipoint plate dresser, and $36 \%$ decrease for the singlepoint diamond dresser (Fig. 7).

\section{Conclusion}

The studies have shown that with the increase of the dressing process feed, the influence of selecting the type of diamond dressing tool on the roughness parameters $R a, R_{z}$ and $R_{m r(50)}$ of the grinded surfaces increases.

It has been established that at high dressing feed 
rates, surfaces with lower $R a$ and $R$ z roughness parameters and with higher $R_{m r(50)}$ parameter can be obtained by using multi-point powder and disk stationary diamond dressing tools, possibly, because these two types of dressers have wider contact with the grinding wheel during the dressing process, and as a consequence, they have a higher overlap coefficient in comparison with multi-point plate dresser and single-point diamond dresser.

The comparative analysis has shown that the roughness parameters of obtained grinded parts surfaces can differ up to 2.1 times depending on selected diamond dresser and up to 4 times depending on selected dressing feed value in the studied range.

The experiments have shown that the tendency of the dependences of the roughness parameters $R a, R_{z}$. and $R_{m r(50)}$ on the dressing feed for diamond dressing tools does not change substantially at different values of grinding process feed in circular grinding of Ti6Al4V alloy.

\section{Acknowledgment}

This work was supported by the Student Grant Competition of the Technical University of Liberec under the project No. SGS-2019-5034.

\section{References}

[1] LATTNER, R., HOLEŠOVSKÝ, F., NOVÁK, M., VRABEL, M. (2016). Grinding of Titanium Alloy Ti6Al4V with Silicon Carbide Grinding Wheel, Manufacturing Technology, Vol. 16, No. 1, pp. 159-162. Univerzita J. E. Purkyne. ISSN 12132489

[2] LATTNER, R., HOLEŠOVSKÝ, F., KAREL, T., LATTNER, M. (2015). Abrasive machining of Ti6Al4V alloy, Manufacturing Technology, Vol. 15, No. 4, pp. 571-575. Univerzita J. E. Purkyne. ISSN 12132489

[3] KADIVAR, M., AZARHOUSHANG, B., DANESHI, A., KRAJNIK, P. (2020). Surface integrity in micro-grinding of Ti6Al4V considering the specific micro-grinding energy, Procedia CIRP, Vol. 33, No. 13, pp. 13. Elsevier B.V. ISSN 22128271

[4] RAJ RAI, B., MUKHOPADHYAY, M., KUMAR KUNDU, P. (2019). Evaluating the grinding ratio and surface quality of Ti-6Al-4V under varying grinding pass count and depth of cut, Joumal of Physics: Conference Series 2019, Vol. 1240, No. 1, Article number 012143. Institute of Physics Publishing. ISSN 17426588

[5] MUKHOPADHYAY, M., KUNDU, P.K. (2018). Optimization of dressing infeed of alumina wheel for grinding Ti-6Al-4V, Materials and Manufacturing Processes, Vol. 33, No. 13, pp. 1453-1458. Taylor and Francis Inc. ISSN 10426914

[6] MUKHOPADHYAY, M., KUNDU, P.K., CHATTERJEE, S., DAS, S. (2019). Impact of dressing infeed on $\mathrm{SiC}$ wheel for grinding Ti6Al-4V, Materials and Manufacturing Processes, Vol. 34, No. 1, pp. 54-60. Taylor and Francis Inc. ISSN 10426914

[7] KADIVAR, M., AZARHOUSHANG, B., SHAMRAY, S., KRAJNIK, P. (2018). The effect of dressing parameters on micro-grinding of titanium alloy, Precision Engineering, Vol. 51, pp. 176-185. Elsevier Inc. ISSN 01416359

[8] LI, M., DING, W., LI, B., XU, J. (2019). Morphological evolution and grinding performance of vitrified bonded microcrystal alumina abrasive wheel dressed with a single-grit diamond, Ceramics International, Vol. 45, No. 16, pp. 19669-19678. Elsevier Ltd. ISSN 02728842

[9] NOVÁK, M., NÁPRSTKOVÁ, N., KASUGA, H. (2016). Influence of grinding wheel dressing on the roughness of final surface and cutting force during GGG60 grinding, Key Engineering Materials, Vol. 686, pp. 218-223. Trans Tech Publications Ltd. ISSN 10139826

[10] LINKE, B. (2008). Dressing process model for vitrified bonded grinding wheels, CIRP Annals - Manufacturing Technology, Vol. 57, No. 1, pp. 345-348. Elsevier USA. ISSN 00078506

[11] PACITTI, V., RUBENSTEIN, C. (1972). The influence of the dressing depth of cut on the performance of a single point diamond dressed alumina grinding wheel, International Journal of Macbine Tool Design and Research, Vol. 12, No. 4, pp. 267-279. ISSN 00207357

[12] BUTTERY, T.C., STATHAM, A., PERCIVAL, J.B., HAMED, M.S. (1979). Some effects of dressing on grinding performance. Wear, Vol. 55, No. 2, pp. 195-219. ISSN 00431648

[13] HOLESOVSKY, F., PAN, B., MORGAN, M.N., CZAN, A. (2018). Evaluation of diamond dressing effect on workpiece surface roughness by way of analysis of variance, Tehnicki Vjesnik, Vol. 25, pp. 165-169. Strojarski Facultet. ISSN 13303651

[14] MOCHIDA, S., NISHIOKA, T., KUBO, A., TAMAKI, J. (2010). Evaluation of diamond dressers and estimation of grinding performance by dressing force measurement, International Journal of Abrasive Technology, Vol. 3, No. 1, 
pp. 37-50. Inderscience Publishers. ISSN 17522641

[15] DING, W., LI, H., ZHANG, L., XU, J., FU, Y., SU, H. (2017). Diamond wheel dressing: A comprehensive review, Journal of Manufacturing Science and Engineering, Transactions of the ASME, Vol. 139, No. 12, 121006. American Society of
Mechanical Engineers (ASME). ISSN 10871357

[16] GODINO, L., POMBO, I., SANCHEZ, J.A., MENDEZ, I., CEARSOLO, X. (2017). Analysis of the dressing process using stationary dressing tools, Procedia Manufacturing, Vol. 13, pp. 146-152. Elsevier B.V. ISSN 23519789 